\title{
Dose-Volume Prediction of Radiation- Related Complications after Hypofractionated Conformal Radiotherapy for Brain Metastases in Critical Areas
}

Hiroshi K. Inoue ${ }^{1}$, Hiro Sato ${ }^{2}$, Yoshiyuki Suzuki ${ }^{2}$, Jun-ichi Saitoh ${ }^{2}$, Shin-ei Noda ${ }^{2}$, Ken-ichi Seto $^{3}$, Kota Torikai ${ }^{4}$, Takashi Nakano ${ }^{5}$

1. Dept of Neurosurgery and Radiation Oncology, Institute of Neural Organization and Cyber Center, Kanto Neurosurgical Hospital 2. Department of Radiation Oncology, Gunma University Graduate School of Medicine 3. Cyberknife center, Kanto Neurosurgical Hospital 4. Gunma University Heavy-ion Medical Research Center, Gunma University 5. Radiation Oncology, Gunma University

$\square$ Corresponding author: Hiroshi K. Inoue, chair.ino@instno-med.org Disclosures can be found in Additional Information at the end of the article

\section{Abstract}

The use of hypofractionated radiotherapy to treat brain metastases and other lesions in critical areas demands an accurate understanding of the risks of complication.

We therefore analyzed risk factors for predicting complications after hypofractionation treatment (two to 10 fractions) for brain metastases based on data for 470 lesions in 367 patients treated with conformal radiotherapy using the CyberKnife.

Twenty-seven lesions in 24 patients exhibited complications over a median follow-up period of seven months (2-50 months). The tumor and brain volumes circumscribed with a single dose equivalent (SDE) of $14 \mathrm{~Gy}$ (V14) were found to be significant factors of complications in a univariate analysis. However, the V14 was the only significant factor in the multivariate analysis.

Other risk factors were analyzed based on differences between the groups in the characteristics of the 27 lesions. Consequently, the tumor location (cerebrum, $\mathrm{p}=0.003)$, tumor volume ( $\geqslant$ $\left.10 \mathrm{~cm}^{3}, \mathrm{p}=0.01\right)$, SDE of the maximum dose $(\geqslant 40 \mathrm{~Gy}, \mathrm{p}=0.01)$, and V14 $\left(\geqslant 3 \mathrm{~cm}^{3}, \mathrm{p}=0.001\right)$ were identified to be significant predictive factors according to the t-test, while the marginal dose $(\geqslant$ $31 \mathrm{~Gy}$ ) and fraction number ( $\leqslant$ five) were found to be borderline significant.

Received 07/08/2014 Review began 07/11/2014 Review ended 07/18/2014 Published 07/21/2014

\section{C) Copyright 2014}

Inoue et al. This is an open access article distributed under the terms of the Creative Commons Attribution License CC-BY 3.0., which permits unrestricted use, distribution, and reproduction in any medium, provided the original author and source are credited.
The actual risk of complications after hypofractionated conformal radiotherapy can be best predicted using a model that accounted for the SDE of the maximum dose and V14.

Categories: Radiation Oncology, Neurosurgery

Keywords: brain edema, radiation necrosis, dose-volume prediction, complication risks, predictive factors, large brain metastases, hypofractionated conformal radiotherapy, multi-session radiosurgery, brain volumes, v14

\section{Introduction}

Radiosurgery is an important therapeutic tool for the treatment of brain metastases in multiple 
clinical settings. The addition of radiosurgery to whole brain radiotherapy (WBRT) may improve intracranial tumor control compared to WBRT alone in selected patients [1-2], and radiosurgery is commonly used as salvage therapy for intracranial tumor progression after WBRT. Moreover, radiosurgery is increasingly used as a primary treatment modality in an attempt to prevent disturbances of neurocognitive function after WBRT [3]. However, single-session radiosurgery has dose limitations for treating large metastases with respect to preventing adverse effects on surrounding structures, such as the optic pathway and brainstem. Surgery is essential in patients with large brain metastases that cause progressive symptoms, such as hemiparesis or a disturbance of consciousness, although surgical removal carries a risk of inducing neurological deficits following the dissection of functional areas. Surgery also requires hospitalization for at least one week, with higher medical expenses than radiosurgery in this country.

Hypofractionated radiotherapy appears to be beneficial for metastases not causing clinical signs of impending cerebral herniation, and its use is supported by the findings of previously published series employing varying radiation doses and fractionation schedules [4-8]. However, the optimal dose and fraction have not yet been established, and the exact incidence of complications on the surrounding brain is unclear, especially in cases involving large tumors [8]. Morbidity, and even mortality, has been reported after fractionated radiosurgery for large brain metastases [9-10]. We previously reported the efficacy and toxicity of three-fraction and five-fraction radiotherapy for brain metastases in critical areas and recommended that larger fraction numbers should be selected for large brain metastases based on the dose-volume effects on the surrounding brain circumscribed with a single dose equivalent (SDE) of $14 \mathrm{~Gy}$ (V14: defined based on experiences of radiosurgery) to avoid radiation necrosis [11-12]. Although the dose-volume prediction of radiation-related complications is widely known to be effective in preventing radiation necrosis in patients undergoing single-session radiosurgery [13], there are currently no data for predicting complications after hypofractionation. The V14 seems to be a useful indicator for comparing the incidence of complications among various fractions after hypofractionated radiotherapy [14].

This report first presents predictive factors and the probability of complications of hypofractionation treatment performed at this institution as a useful treatment for brain metastases in critical areas in comparison with that observed in cases of single-session radiosurgery.

\section{Materials And Methods}

All patients with brain metastases provided their written informed consent prior to undergoing the procedures and were treated with single-fraction radiosurgery or hypofractionated conformal radiotherapy at Kanto Neurosurgical Hospital between March 2005 and October 2013. Hypofractionated treatment (two to 10 fractions) was performed in 392 patients. The incidence of radiation-related complications was evaluated in relation to patients' age, sex, tumor location, tumor volume, prescribed isodose, marginal dose, fraction number, the surrounding brain volume (V14), and others.

\section{Definition of variables and end points}

The treatment dose is expressed as the marginal dose used in hypofractionated radiotherapy. The maximum dose was obtained from the marginal dose and prescribed isodose for the lesion margin. A complication was defined as a neurological impairment (either the development of a new deficit or the significant deterioration of a pre-existing or recurrent deficit) and change in imaging studies after treatment. For all symptomatic complications, either computerized tomography scans or magnetic resonance imaging studies were examined. Clinical follow-up was considered to have stopped at the time of the most recent report from the patient or a representative or at the time of death. 


\section{Cureus}

\section{Inclusion and exclusion criteria}

Three hundred and ninety-two patients were treated and found eligible for inclusion in this study. Twenty-five patients (6.4\%) were excluded from the analysis because imaging studies were not available after treatment. All other patients (367) were included in the analysis.

\section{Patient characteristics}

The median age of the patients was 68 years; 173 patients (47.1\%) were 65 years of age or older. The primary cancers were located in the lungs, breast, gastrointestinal tract, kidney, uterus, larynx, ovary, or other regions (thyroid, liver, bladder, etc.). The tumors $(n=470)$ treated with the hypofractionation protocol were located in and around critical areas previously reported [12]. Those were in the cerebral hemisphere, thalamus/basal ganglia, brainstem, and cerebellum. The median tumor volume of the 470 lesions was $8.8 \mathrm{~cm}^{3}$. One hundred and fifteen tumors (24.5\%) were larger than $15 \mathrm{~cm}^{3}$ (more than $3 \mathrm{~cm}$ in diameter). Thirty-one tumors measured $30 \mathrm{~cm}^{3}$ or more in size, up to $78 \mathrm{~cm}^{3}$. Table 1 (left line) shows the patient characteristics. 


\section{Cureus}

\section{Characteristics of patients}

Number of patients

Median age (range)

Age $\geq 65$

Age $<65$

Sex

Male

Female

Location of tumor

Cerebral hemisphere

Frontal

Parietal

Temporal

Occipital

Thalamus, basal ganglia

Brainstem

Cerebellum

Tumor volume, median $\left(\mathrm{cm}^{3}\right)$

$\geq 30.0$

20.0-29.9

10.0-19.9

$<10.0$

Follow-up period (months)

Median

Range
367

$68(28-93)$

173

194

189

178

470 lesions

322

132

60

54

76

29

32

87

8.8

31

37

126

276

$2-50$
Treatment-related variables

Prescribed isodose (\%)

Median

58

Range

49-77

Marginal dose (Gy)

Median

30

Range

$18-48$

Fraction number

Median 3

Range $\quad 2-10$

Lesions treated with 2-fraction 20

3-fraction 226

4-fraction 20

5-fraction 156

6-fraction 16

8-fraction 22

10-fraction 10

Maximum dose (SDE, Gy)

Median

46.4

Range

24.9-65.8

$\mathrm{V} 14\left(\mathrm{~cm}^{3}\right)$

Median

4.9

Range

$0-36.9$

Complications

27

(radiation edema, necrosis)

$(21,6)$

TABLE 1: Characteristics of the patients treated for brain metastases in critical areas with hypofractionated conformal radiotherapy

\section{Hypofractionated conformal radiotherapy}




\section{Cureus}

All patients evaluated in this study were treated consecutively with two to 10 fractions over sequential days using the CyberKnife (Accuray, Sunnyvale, CA). Patients with perifocal brain edema and symptoms were treated with the concomitant intravenous administration of glycerol and beta-methasone (osmo-steroid therapy). All treatment procedures were performed under computed tomography (CT) and MRI guidance, as previously reported [12]. Tumors located in and around critical areas, such as the motor cortex, thalamus, and brainstem, were intended to treat with a marginal dose of 26-35 Gy in two to five fractions depending on the size of the tumor. A marginal dose of 31-42 Gy in five to 10 fractions was intended to use to treat large tumors in order to decrease the incidence of adverse effects on the surrounding brain. The dose to the optic pathway (optic nerve, chiasm, and tract) was intended to be less than 10.8 to $20 \mathrm{~Gy}$ in two to 10 fractions rather than 12.3 to $30.2 \mathrm{~Gy}$ (the normal tissue dose constraint for the optic pathway in two- to ten-fraction treatment, an equivalent dose of $8 \mathrm{~Gy}$ in single-fraction treatment) [15] in order to reduce the risk of adverse effects (Table 2).

\begin{tabular}{|c|c|c|c|c|c|c|c|c|}
\hline SDE & & 2-fraction & 3-fraction & 4-fraction & 5-fraction & 6-fraction & 8-fraction & 10-fraction \\
\hline \multirow[t]{3}{*}{8 Gy } & This study & 10.8 Gy & $12.8 \mathrm{~Gy}$ & $14.3 \mathrm{~Gy}$ & $15.6 \mathrm{~Gy}$ & 16.7 Gy & $18.5 \mathrm{~Gy}$ & $20.0 \mathrm{~Gy}$ \\
\hline & Timmerman & 12.3 Gy $^{*}$ & $15.3 \mathrm{~Gy}$ & 19.2 Gy & $23.0 \mathrm{~Gy}$ & $24.2 \mathrm{~Gy}^{\star}$ & $27.2 \mathrm{~Gy}$ & $30.2 \mathrm{~Gy}^{\star}$ \\
\hline & Timmerman2 & 11.6 Gy & & & & $24.4 \mathrm{~Gy}$ & & $30.6 \mathrm{~Gy}$ \\
\hline \multirow[t]{3}{*}{14 Gy } & This study & 19.3 Gy & 23.1 Gy & 26.2 Gy & $28.8 \mathrm{~Gy}$ & $31.2 \mathrm{~Gy}$ & $35.1 \mathrm{~Gy}$ & 38.4 Gy \\
\hline & Timmerman & $18.5 \mathrm{~Gy}^{*}$ & 22.5 Gy & $25.6 \mathrm{~Gy}$ & $28.0 \mathrm{~Gy}$ & $31.8 \mathrm{~Gy}^{\star}$ & 33.6 Gy & 39.8 Gy \\
\hline & Timmerman2 & 18.3 Gy & & & & 29.9 Gy & & $36.0 \mathrm{~Gy}$ \\
\hline
\end{tabular}

TABLE 2: The single dose equivalent (SDE) of $8 \mathrm{~Gy}$ and $14 \mathrm{~Gy}$ in two- to ten-fraction treatment was selected and obtained based on the normal tissue dose constraint according to Timmerman's values [15]

*Doses at the 2-, 6- and 10-fraction levels were estimated according to a fitted cubic equation curve. Original data for the fitted curve was acquired from Timmerman and calculated using the least squares method [15]. Doses at the 2-, 6- and 10-fraction levels of the Timmerman2 (personal communication) were calculated with linear interpolations between the table values.

\section{Prescribed marginal doses and SDE of the maximum dose}

The maximum dose was calculated from the marginal dose and prescribed isodose (ex. the maximum dose of a plan with marginal dose of $30 \mathrm{~Gy}$ at an isodose of $50 \%$ calculated was as 60 Gy). For the purpose of dose-response analyses, the maximum dose in two- to ten-fraction treatment was converted to SDE using the equation reported by Eaton, et al. and Park, et al. [8, 16] where D equals the total dose and a Dq of 1.8 .

$\mathrm{SDE}=\mathrm{D}-(\mathrm{n}-1) \times \mathrm{Dq}$

(Ex. The SDE of the maximum dose of $60 \mathrm{~Gy}$ in three-fraction treatment calculated as 60 - (3 1) $\mathrm{x} 1.8=56.4 \mathrm{~Gy}$ )

\section{Evaluation of the brain volume around the lesions}

The V14 (brain volume circumscribed with an SDE of $14 \mathrm{~Gy}$ ) was measured and recorded in each patient in order to compare the risk of complications on the surrounding brain among the 
different two- to 10-fraction treatments. An SDE of $14 \mathrm{~Gy}$ (19.3 Gy in two-fraction to $38.4 \mathrm{~Gy}$ in 10 -fraction) instead of 18.5 to $39.8 \mathrm{~Gy}$ (the normal tissue dose constraint for the spinal cord in two- to ten-fraction treatment, an equivalent dose of $14 \mathrm{~Gy}$ in single-fraction treatment) [15] was used (Table 2) for the dose-response analyses. The V14, as well as the tumor volumes, was calculated as previously reported [12].

\section{Follow-up evaluations and complications}

Changes in neurological symptoms, such as paresis, sensory disturbances, aphasia, and visual disturbances, were examined after treatment. Serial imaging studies (MRI or CT) were requested six weeks after treatment and every two to three months thereafter. Complications were identified in association with neurological deterioration and imaging changes in the concomitant perifocal regions after treatment.

\section{Statistical analysis}

The univariate and multivariate analyses were performed using logistic regression and Cox hazard models. Differences between the groups were evaluated using Student's t-test. All analyses used the conventional $\mathrm{p}<0.05$ level of significance.

\section{Results}

Four hundred and seventy lesions treated with hypofractionation were analyzed for the incidence of complications in relation to the predictive factors. The prescribed isodoses ranged from $49-77 \%$ (median, 58\%). The marginal dose ranged from 18-48 Gy (median, $30 \mathrm{~Gy}$ ). The treatment-related and post-treatment variables of 470 brain metastases are shown in Table 1 (right line). No new neurological deficits were observed in patients with lesions in or around critical areas, such as the optic pathway and brainstem.

\section{Complications and predictive factors}

Twenty-seven lesions in 24 patients resulted in symptomatic complications (Table 3). 


\section{Cureus}

\section{Characteristics of patients}

Number of patients

Median age (range)

Age $\geq 65$

Age $<65$

Sex

Male

Female

Location of tumor

Cerebral hemisphere

Frontal

Parietal

Temporal

Occipital

Basal ganglia

Cerebellum

Tumor volume, median $\left(\mathrm{cm}^{3}\right)$

$\geq 30.0$

20.0-29.9

10.0-19.9

$<10.0$
$59(38-84)$

9

15

11

13

27 lesions

25

9

3

5

8

1

1

16.8

4

8

5

10

\section{Treatment-related variables}

Prescribed isodose (\%)

Median

58

Range

$51-65$

Marginal dose (Gy)

Median

31

Range

27-36

Fraction number

Median

5

Range

3-8

Lesions treated with 3-fraction

9

4-fraction 1

5-fraction 12

6-fraction 2

8-fraction 3

Maximum dose (SDE, Gy)

Median

47.3

Range

39.3-58.8

$\mathrm{V} 14\left(\mathrm{~cm}^{3}\right)$

Median

5.4

Range

\section{TABLE 3: Characteristics of the 27 lesions with complications after hypofractionated}

conformal radiotherapy

The median age of the patients was 59 years, with 15 subjects under 65 years of age. There were 13 females and 11 males. The tumor was located in the basal ganglia in one patient, the cerebellum in one patient and the cerebrum in 24 patients (frontal - 9, occipital - 8, temporal 5 , and parietal - 3). The median tumor volume was $16.8 \mathrm{~cm}^{3}$, and 17 tumors measured $10 \mathrm{~cm}^{3}$ or more in size. The median prescribed isodose was 58\%, and 18 lesions were treated with an isodose of $60 \%$ or less. The median marginal dose was $31 \mathrm{~Gy}$, and 15 lesions received a dose of $31 \mathrm{~Gy}$ or more. The median fraction number was five, and 22 lesions were treated with five fractions or less. The median SDE of the maximum dose was $47.3 \mathrm{~Gy}$, and 26 lesions received an 


\section{Cureus}

SDE of 40 Gy or more. The median V14 was $5.4 \mathrm{~cm}^{3}$, and all 27 lesions were treated with a V14 of $3.0 \mathrm{~cm}^{3}$ or more.

In the univariate analyses using logistic regression and Cox hazard models, the tumor volume and V14 were found to be significant factors for complications. However, only the V14 was identified to be significant in the multivariate analyses (Table 4).

\begin{tabular}{|c|c|c|c|c|c|}
\hline Factor & OR & Univariate $95 \% \mathrm{Cl}$ & $p$ value & Cox hazard p value & Multivariate $p$ value \\
\hline Age (per decade) & 0.86 & $0.64-1.15$ & 0.32 & 0.84 & 0.82 \\
\hline Sex & 0.62 & $0.28-1.37$ & 0.24 & 0.61 & 0.19 \\
\hline Location & 1.06 & 0.87-1.31 & 0.56 & 0.81 & 0.25 \\
\hline Tumor volume & 1.04 & $1.01-1.06$ & $0.005^{x}$ & $0.007^{x}$ & 0.38 \\
\hline Isodose & 0.96 & 0.89-1.03 & 0.29 & 0.32 & 0.19 \\
\hline Marginal dose & 1.08 & 0.98-1.19 & 0.12 & 0.19 & 0.27 \\
\hline Fraction & 1.21 & 0.99-1.48 & 0.06 & 0.17 & 0.43 \\
\hline SDE of max. Dose & 1.04 & $0.98-1.11$ & 0.19 & 0.19 & 0.26 \\
\hline V14 & 1.14 & $1.05-1.23$ & $0.002^{*}$ & $0.006^{*}$ & $0.01^{*}$ \\
\hline
\end{tabular}

TABLE 4: Results of the univariate and multivariate analyses of risk factors for complications in the $\mathbf{4 7 0}$ lesions

OR: odds ratio, $\mathrm{Cl}$ : confidence interval, *significant

Differences in each risk factor between the groups were analyzed using the t-test (Table 5). 


\section{Cureus}

\begin{tabular}{|c|c|c|c|}
\hline Factor & Group 1 (n) & Group 2 (n) & $p$ value \\
\hline Age & $\geq 65$ y (9) & < 65 y (15) & 0.16 \\
\hline Sex & $F(13)$ & M (11) & 0.28 \\
\hline \multirow[t]{3}{*}{ Location } & cerebrum (25) & other (2) & $0.003^{\star}$ \\
\hline & frontal (9) & parietal (3) & 0.32 \\
\hline & basal ganglia (1) & others (26) & 0.29 \\
\hline Tumor volume & $\geq 10 \mathrm{~cm}^{3}$ (17) & $<10 \mathrm{~cm}^{3}(10)$ & $0.01^{\star}$ \\
\hline Isodose & $>60 \%(9)$ & $\leq 60 \%(18)$ & 0.38 \\
\hline Marginal dose & $\geq 31$ Gy (15) & $<31$ Gy (12) & 0.05 \\
\hline Fraction number & $>5(5)$ & $\leq 5(22)$ & 0.06 \\
\hline SDE of max. dose & $\geq 40$ Gy (26) & $<40$ Gy (1) & $0.01^{*}$ \\
\hline V14 & $\geq 3 \mathrm{~cm}^{3}(27)$ & $<3 \mathrm{~cm}^{3}(0)$ & $0.001^{*}$ \\
\hline
\end{tabular}

TABLE 5: Risk factors for complications in the $\mathbf{4 7 0}$ lesions between the two groups analyzed using the t-test

*significant

Consequently, the tumor location (cerebrum), tumor volume $\left(\geqslant 10 \mathrm{~cm}^{3}\right)$, SDE of the maximum dose $(\geqslant 40 \mathrm{~Gy})$, and V14 $\left(\geqslant 3 \mathrm{~cm}^{3}\right)$ were shown to be significant factors for complications, whereas the marginal dose $(\geqslant 31 \mathrm{~Gy})$ and fraction number $(\leqslant 5)$ were borderline significant. Meanwhile, the SDE of the maximum dose and the V14 were more significant than the marginal dose and tumor volume, respectively.

\section{V14 values of the surrounding nrain and complications}

The V14 was plotted in relation to the SDE of the maximum dose (Figure 1). 


\section{Cureus}

Fig. 1

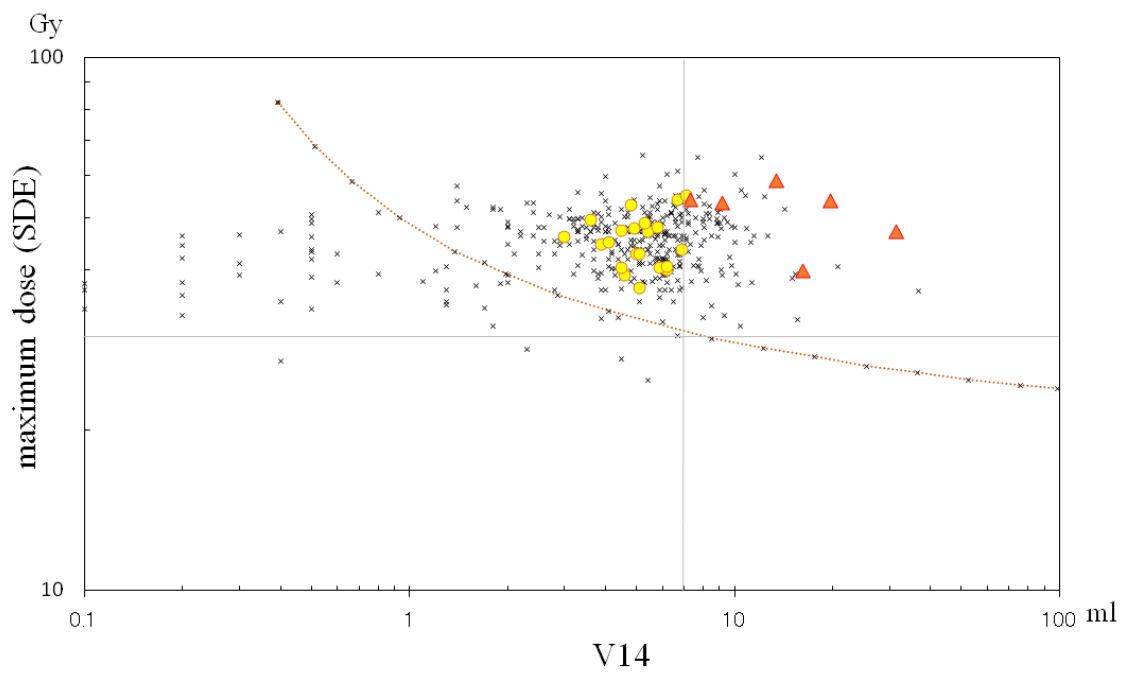

\section{FIGURE 1: Scatterplot showing dose-volume interaction.}

V14 values of 470 brain metastases plotted in relation to the SDE values of the maximum doses administered in hypofraction treatment. Symptomatic complications developed in 27 lesions, brain edema in 21 lesions (round) and radiation necrosis requiring surgical resection in six lesions (triangle). Kjellberg's 5\% necrosis risk line [13] was converted and then drawn for fivefraction radiotherapy (dotted line).

The actual risk of complications was best predicted using a model accounting for the maximum dose (SDE) and V14. Lesions treated with a higher SDE of the maximum dose of $40 \mathrm{~Gy}$ or more and a V14 of $3 \mathrm{~cm}^{3}$ or more exhibited a higher risk of complications than those treated with lower doses and lower V14 values. Notably, lesions treated with a V14 more than $7 \mathrm{~cm}^{3}$ carried a risk of irreversible complications.

\section{Discussion}

The role of radiosurgery has been described in 10 institutional studies of patients treated with radiosurgery and WBRT [17]. Radiosurgery also plays a role in the treatment of small multiple brain metastases in advanced cancer patients due to the short treatment time and absence of the need for general anesthesia. However, the treatment of large metastases in critical areas has dose limitations for single-fraction radiosurgery. The dose-volume prediction of complications after single-session radiosurgery has been reported [13] and widely used as the Kjellberg risk line. Blonigen, et al. and Minniti, et al. proposed that patients with a V10 Gy of > $10.5 \mathrm{~cm}^{3}$ or V12 Gy of $>7.9 \mathrm{~cm}^{3}$ and V12 Gy of $>8.5 \mathrm{~cm}^{3}$ should be considered for hypofractionated radiotherapy, respectively [18-19]. The dose-volume prediction of complications after hypofractionated radiotherapy is required, as in single-session radiosurgery, to avoid complications.

In order to predict complications after hypofractionation treatment, the SDE in two- to tenfraction treatment must be calculated. However, the exact calculation method for obtaining the proper single dose equivalent of $14 \mathrm{~Gy}$ in hypofractionated radiotherapy has not yet been established. A generalized linear-quadratic model appears to be suitable for this calculation [20-21]. We used an SDE of $8 \mathrm{~Gy}$ and $14 \mathrm{~Gy}$, referring to Timmerman's report. The accumulation of clinical data regarding the use of the SDE, which can be converted for proper SDE in the future, may support the creation of an ideal calculation method for converting to SDE from 
hypofractionation.

We previously reported the efficacy and toxicity of three- and five-fraction treatment for brain metastases and suggested that the V14 is a useful indicator of radiation necrosis. [11-12]. In the present study based on data for 470 lesions, the statistical analyses of risk factors for complications showed the V14 to be a significant factor according to the univariate and multivariate analyses. The V14 values can be decreased, even in patients with large lesions undergoing hypofractionation treatment. In contrast, the tumor volume is not always a significant factor, as shown in the present multivariate analyses. The V14 is thus not only an indicator of necrosis, but also a best predictive factor of complications.

We analyzed the differences between the groups based on the characteristics of the 27 lesions. Consequently, the SDE of the maximum dose ( $\geqslant 40 \mathrm{~Gy})$ and V14 $(\geqslant 3 \mathrm{~cm} 3)$ were found to be significant factors according to the t-test. The maximum dose, treatment volume, location (thalamus/brainstem) and patient' age have been shown to be predictive factors of radiation necrosis in patients undergoing single-session radiosurgery [13, 19, 22]. However, in the current series, the location of thalamic/brainstem lesions and the patient' age were not identified to be significant factors, and no complications were detected in the patients with brainstem lesions. It is possible to decease the dose to surrounding critical structures while maintaining a proper treatment dose for the lesion when applying hypofractionated conformal radiotherapy. Hypofractionation treatment is thus safe and less invasive for patients with high risk factors, such as large lesions or those located in critical areas, as well as elderly patients and/or individuals with general risks for surgery.

As to the results of the univariate and multivariate analyses, the t-test for differences between the groups, showed the V14 and SDE of the maximum dose to be important predictive factors for complications after hypofractionated radiotherapy. The actual risk of complications was best predicted using a model accounting for the maximum dose (SDE) and V14, as shown in Figure 1. In addition, Kjellberg's 5\% necrosis risk line converted and drawn for five-fraction radiotherapy appeared to fit the current dose-volume prediction model; no lesions appeared on the $5 \%$ risk line in this series. Therefore, the percent risk of necrosis can be decreased in patients undergoing hypofractionation treatment more easily than in those undergoing singlesession radiosurgery. In the present series, large lesions measuring $30 \mathrm{~cm}^{3}$ or more were treated in 31 patients, four of whom developed symptomatic complications. One patient received surgery for radiation necrosis, while three patients treated with a V14 less than $7 \mathrm{~cm}^{3}$ recovered from their complications and survived up to 18 months after treatment. Hence, the $5 \%$ necrosis risk line after hypofractionation treatment was drawn on a level higher than the maximum dose, versus Kjellberg's 5\% necrosis risk line shown in Figure 1.

The Kjellberg risk line indicates the safe treatment dose for larger lesions in order to avoid radiation necrosis in single-session radiosurgery. Large lesions should be treated with doses below the risk line in patients undergoing single-session treatment. The current dose-volume prediction analysis suggests the proper dose and fraction number for hypofractionation treatment of large lesions in the brain. Therefore, the treatment dose and V14 can be decreased in reference to the results of this prediction analysis using an optimal dose and fraction for the treatment of large lesions in patients receiving hypofractionated radiotherapy.

\section{Conclusions}

We herein reported predictive factors of complications after hypofractionated conformal radiotherapy for brain metastases. The actual risk of complications is best predicted using a model that accounted for the SDE of the maximum dose and V14. Assessing the brain volume (V14) is useful for preventing complications and appears to be helpful for determining the 
optimal dose and fraction number for hypofractionation treatment of large brain lesions in critical areas.

\section{Additional Information Disclosures}

Human subjects: Consent was obtained by all participants in this study. Animal subjects: All authors have confirmed that this study did not involve animal subjects or tissue. Conflicts of interest: In compliance with the ICMJE uniform disclosure form, all authors declare the following: Payment/services info: All authors have declared that no financial support was received from any organization for the submitted work. Financial relationships: All authors have declared that they have no financial relationships at present or within the previous three years with any organizations that might have an interest in the submitted work. Other relationships: All authors have declared that there are no other relationships or activities that could appear to have influenced the submitted work.

\section{References}

1. Kondziolka D, Patel A, Lunsford LD, Kassam A, Flickinger JC: Stereotactic radiosurgery plus whole brain radiotherapy versus radiotherapy alone for patients with multiple brain metastases. Int J Radiat Oncol Biol Phys. 1999, 45:427-34.

2. Andrews DW, Scott CB, Sperduto PW, Flanders AE, Gaspar LE, Schell MC, Werner-Wasik M, Demas W, Ryu J, Bahary JP, Souhami L, Rotman M, Mehta MP, Curran WJ Jr: Whole brain radiation therapy with or without stereotactic radiosurgery boost for patients with one to three brain metastases: Phase III results of the RTOG 9508 randomised trial. Lancet. 2004, 363:1665-72.

3. Chang EL, Wefel JS, Hess KR, Allen PK, Lang FF, Kornguth DG, Arbuckle RB, Swint JM, Shiu AS, Maor MH, Meyers CA: Neurocognition in patients with brain metastases treated with radiosurgery or radiosurgery plus whole-brain irradiation: A randomised controlled trial. Lancet Oncol. 2009, 10:1037-44. 10.1016/S1470-2045(09)70263-3

4. Aoyama H, Shirato H, Onimaru R, Kagei K, Ikeda J, Ishii N, Sawamura Y, Miyasaka K: Hypofractionated stereotactic radiotherapy alone without whole-brain irradiation for patients with solitary and oligo brain metastasis using noninvasive fixation of the skull. Int J Radiat Oncol Biol Phys. 2003, 56:793-800.

5. Lindvall P, Bergström P, Löfroth PO, Henriksson R, Bergenheim AT: Hypofractionated conformal stereotactic radiotherapy alone or in combination with whole-brain radiotherapy in patients with cerebral metastases. Int J Radiat Oncol Biol Phys. 2005, 61:1460-6.

6. Marchetti M, Milanesi I, Falcone C, De Santis M, Fumagalli L, Brait L, Bianchi L, Fariselli L: Hypofractionated stereotactic radiotherapy for oligometastases in the brain: A singleinstitution experience. Neurol Sci. 2011, 32:393-9. 10.1007/s10072-010-0473-4

7. Ogura K, Mizowaki T, Ogura M, Sakanaka K, Arakawa Y, Miyamoto S, Hiraoka M: Outcomes of hypofractionated stereotactic radiotherapy for metastatic brain tumors with high risk factors. J Neurooncol. 2012, 109:425-32. 10.1007/s11060-012-0912-6

8. Eaton BR, Gebhardt B, Prabhu R, Shu HK, Curran WJ Jr, Crocker I: Hypofractionated radiosurgery for intact or resected brain metastases: Defining the optimal dose and fractionation. Radiat Oncol. 2013, 8:135. 10.1186/1748-717X-8-135

9. Han JH, Kim DG, Chung HT, Paek SH, Park CK, Jung HW: Radiosurgery for large brain metastases. Int J Radiat Oncol Biol Phys. 2012, 83:113-20. 10.1016/j.ijrobp.2011.06.1965

10. Jiang XS, Xiao JP, Zhang Y, Xu YJ, Li XP, Chen XJ, Huang XD, Yi JL, Gao L, Li YX: Hypofractionated stereotactic radiotherapy for brain metastases larger than three centimeters. Radiat Oncol. 2012, 7:36. 10.1186/1748-717X-7-36

11. Inoue HK, Seto K, Nozaki A, Torikai K, Suzuki Y, Saitoh J, Noda SE, Nakano T: Three-fraction CyberKnife radiotherapy for brain metastases in critical areas: Referring to the risk evaluating radiation necrosis and the surrounding brain volumes circumscribed with a single dose equivalence of 14 Gy (V14). J Radiat Res. 2013, 54:727-35. 10.1093/jrr/rrt006

12. Inoue HK, Sato H, Seto K, Torikai K, Suzuki Y, Saitoh J, Noda SE, Nakano T: Five-fraction 
CyberKnife radiotherapy for large brain metastases in critical areas: Impact on the surrounding brain volumes circumscribed with a single dose equivalent of $14 \mathrm{~Gy}$ (V14) to avoid radiation necrosis. J Radiat Res. 2014, 55:334-42. 10.1093/jrr/rrt127

13. Barker FG 2nd, Butler WE, Lyons S, Cascio E, Ogilvy CS, Loeffler IS, Chapman PH: Dosevolume prediction of radiation-related complications after proton beam radiosurgery for cerebral arteriovenous malformations. J Neurosurg. 2003, 99:254-63.

14. Inoue HK: Characteristics of radiosurgery. Textbook of Radiosurgery. Inoue HK (ed): Medica Press, Osaka, Japan; 2012. pg 14-15.

15. Timmerman RD: An overview of hypofractionation and introduction to this issue of seminars in radiation oncology. Semin Radiat Oncol. 2008, 18:215-22. 10.1016/j.semradonc.2008.04.001

16. Park C, Papiez L, Zhang S, Story M, Timmerman RD: Universal survival curve and single fraction equivalent dose: Useful tools in understanding potency of ablative radiotherapy. Int J Radiat Oncol Biol Phys. 2008, 70:847-52. 10.1016/j.ijrobp.2007.10.059

17. Sanghavi SN, Miranpuri SS, Chappell R, Buatti JM, Sneed PK, Suh JH, Regine WF, Weltman E, King VJ, Goetsch SJ, Breneman JC, Sperduto PW, Scott C, Mabanta S, Mehta MP: Radiosurgery for patients with brain metastases: A multi-institutional analysis, stratified by the RTOG recursive partitioning analysis method. Int J Radiat Oncol Biol Phys. 2001, 51:426-34.

18. Blonigen BJ, Steinmetz RD, Levin L, Lamba MA, Warnick RE, Breneman JC: Irradiated volume as a predictor of brain radionecrosis after linear accelerator stereotactic radiosurgery. Int J Radiat Oncol Biol Phys. 2010, 77:996-1001. 10.1016/j.ijrobp.2009.06.006

19. Minniti G, Clarke E, Lanzetta G, Osti MF, Trasimeni G, Bozzao A, Romano A, Enrici RM: Stereotactic radiosurgery for brain metastases: Analysis of outcome and risk of brain radionecrosis. Radiat Oncol. 2011, 6:48. 10.1186/1748-717X-6-48

20. Wang JZ, Huang Z, Lo SS, Yuh WT, Mayr NA: A generalized linear-quadratic model for radiosurgery, stereotactic body radiation therapy, and high-dose rate brachytherapy. Sci Transl Med. 2010, 2:39ra48. 10.1126/scitranslmed.3000864

21. Iwata H, Matsufuji N, Toshito T, Akagi T, Otsuka S, Shibamoto Y: Compatibility of the repairable-conditionally repairable, multi-target and linear-quadratic models in converting hypofractionated radiation doses to single doses. J Radiat Res. 2013, 54:367-73.

10.1093/jrr/rrs089

22. Flickinger JC, Kano H, Niranjan A, Kondziolka D, Lunsford LD: Dose selection in stereotactic radiosurgery. Prog Neurol Surg. 2013, 27:49-57. 10.1159/000341623 